\title{
New fields for research in the 21st century: proceedings of the 3rd British-Nordic Conference on Library and Information Studies, 12-14 April 1999, Boras, Sweden edited by Maj Klasson, Brendan Loughridge and Staffan Loof 1999, Boras: The Swedish School of Library and Information Studies, University College of Boras, 358pp, ISSN 14000253
}

This volume contains 32 papers presented at a conference attended by 80 teachers and researchers from British and Nordic departments of information and library studies. After two key-note contributions, most of the papers are organised under eight headings, reflecting the plenary sessions of the conference programme as follows: the LIS discipline; knowledge management; the LIS workforce; the electronic environment; impact and consequences; the reflective practitioner; the information environment; and new approaches for the millennium. Seven papers presented at the conference in abbreviated form only are grouped under three further headings representing workshop sessions on assessment; flexible and distance learning; and ethical issues of internet use. The volume concludes with short reports of the workshops, which are separated from the relevant papers.

Lars Hoglund's opening speech is the shortest paper (five pages) and is essentially a welcoming address from the host institution. It provides some background on the Swedish set-up for library and information studies and also picks out issues requiring attention, notably the need for the LIS sector to assert itself, build connections and focus on the most important problems. The first substantial paper is Ian Johnson's confidently-titled 'I have seen the future, and it works' which takes a critical look at the current research landscape and argues the need to sustain effort in areas of enduring importance as well as meeting emerging concerns, while also pursuing alternative funding sources and partnerships.

In a short review it is difficult to do justice to such a large number of individual papers; the reviewer is forced to be selective and tempted to concentrate on content that is distinctive, rather than material which is repackaged or extracted from other sources. Five of the papers published here are based on research projects funded by the British Library Research and Innovation Centre (BLRIC) to investigate various issues related to the education, training and development of information workers in the contemporary environment and a sixth is derived from a BLRIC project on the role of information in the strategic management process. Another paper is based on the series of projects at the University of Northumbria to monitor the IMpact on People of Electronic Libraries (IMPEL), funded as part of the UK Higher Education Funding Councils' Electronic Libraries Programme. These papers contain much of interest to both educators and practitioners but the information is largely accessible elsewhere in articles, reports and papers, including via project Web sites.

Several papers are case studies of different approaches to or aspects of LIS education, covering programme developments at particular institutions, methods of delivery, or specific topics such as professional accreditation, assessment procedures and course evaluation. Others are more issue-based, including James Dearnley's first-hand account of the practical difficulties of teaching students about legislation and case law relating to obscene and pornographic material. Some of the papers are rather loosely connected to the themes of the conference. For example, 'Trust as a basis for knowledge management' by Mirja Iivonen is about current trust practices and potential trust strategies in Finnish public libraries, with discussion of knowledge management limited to a disconnected section at the beginning and another paragraph at the end. The following contribution by Brendan Loughridge happily provides a more thorough and useful assessment of the relevance and implications of knowledge management developments for 
information professionals and their education.

Two papers deserving special mention are the contributions of Claire Warwick and Paul Sturges. In an interesting and thought-provoking piece, Warwick describes how the literary canon is 'reasserting itself electronically' and argues the case for information professionals/bibliographers to be proactive in developing collection policies for electronic text archives. Sturges homes in on the important distinction between information content and the conduit for its delivery, suggesting five areas for focus in the LIS curriculum - and the profession: assessing and filtering content; negotiating ethical and regulatory difficulties; designing user-oriented services; managing knowledge resources; and creating value-added information packages. His title, 'The pursuit of content', while capable of several interpretations, is a fitting reminder of what the primary concern of library and information science should be.

Multi-author works often suffer from a lack of coherence and an unhappy mix of writing styles. The editors of this volume faced the additional challenge of bringing together papers of native English speakers with those for whom English is not their first language. Sadly some of the latter have not been properly edited, which means that the reader is presented with statements such as 'This discipline gives a possibility to...' and 'They will end up to...' Further inconsistencies are evident in the provision of abstracts for only twelve of the papers and some peculiar numbering of sections and sub-sections - in one paper, numbered sections appear only on the last two pages (starting with 3.2) and in another the Introduction is numbered 1.1 and the Conclusion 1.6! Proof-reading has also been neglected: the text is littered with typographical errors, many of them presumably machine-generated. The paper by Stuart Hannabuss on 'Eclectic ethics for an electronic future' is one of the worst examples with misplaced page-breaks and redundant hyphens, giving us numerous oddities such as 'appro-priate', 'competi-tive', 'know-ledge' and 'power-ful'.

Overall this publication is something of a hotchpotch. The subject-matter is wide-ranging but the quality of writing is mixed, with several rather turgid contributions. There are perhaps five or six pieces which I might return to, and maybe more than once for the few papers that I found particularly stimulating. The lack of an index limits the volume's use for reference and I suspect it will appeal more to educators than busy practitioners.

Sheila Corrall 